\title{
USANDO CRIANÇAS PARA VENDER: INFÂNCIA E CONSUMO NA PUBLICIDADE DE REVISTAS
}

\author{
Paula Deporte de Andrade ${ }^{1}$ \\ Marisa Vorraber Costa $^{2}$
}

\section{Resumo}

$\mathrm{Na}$ atual sociedade, também identificada como "sociedade de consumidores" (BAUMAN, 2008), todas as pessoas, independentemente de condições econômicas, gênero, idade e grupo social, são convocadas a fazer parte das redes de consumo. Neste artigo nos voltamos para a infância e abordamos uma das faces de sua inserção na sociedade de consumidores, procurando mostrar como as crianças vem sendo usadas para vender. Como referencial teórico adotamos, entre outros, os escritos de Zygmunt Bauman, Juliet Schor e Robert Bocock que tratam das versões contemporâneas do consumo e as problematizam. A partir da análise da publicidade em revistas semanais de grande circulação, discutimos o quanto é produtivo para o mercado econômico a aliança entre infância e consumo, e argumentamos que esse uso das crianças na publicidade contribui para uma nova concepção de infância: a infância do consumo. Uma infância erotizada, preocupada em adquirir, em mostrar-se, uma infância insaciável e sempre em movimento. É essa infância que está chegando à escola com novos interesses, preferências e condutas, tornando-se merecedora de toda a nossa atenção.

\footnotetext{
${ }^{1}$ Pedagoga, professora da rede pública municipal de Venâncio Aires e Mestranda em Educação pela ULBRA. E-mail paula.deporte@ hotmail.com. Endereço para contato: PPGEDU / ULBRA - Av. Farroupilha, 8001 · Prédio 14, sala 217

- Canoas - RS.

${ }^{2}$ Doutora em Educação e professora dos Programas de Pós-Graduação em Educação da UFRGS e da ULBRA. E-mail: mcvorraber@terra.com.br. Endereço para contato: PPGEDU / ULBRA - Av. Farroupilha, 8001 · Prédio 14, sala 217 Canoas - RS
}

Revista Reflexão e Ação, Santa Cruz do Sul, v.18, n2, p.230-248, jul./dez. 2010 
Palavras-chave: Infância contemporânea; infância e consumo; sociedade de consumidores; publicidade; revistas.

\section{Introdução}

A partir de diferentes estudos sobre a infância, como o conhecido trabalho realizado por Ariès (2006), História social da criança e da família, hoje podemos afirmar que a infância é uma invenção do mundo moderno. Antes as crianças eram vistas como adultos em miniatura, não existia o conceito e o "sentimento de infância" que hoje conhecemos, e não se atribuía a esta fase da vida os significados que começaram a emergir a partir do século XVI. Com isso queremos dizer que, por mais que faça parte do senso comum significar a infância como uma fase da vida caracterizada pela ingenuidade, a dependência e a docilidade, trata-se de uma construção, uma invenção de uma época que foi naturalizada, essencializada e generalizada para todas as crianças. Conforme Bujes (2002):

[...] os significados da infância variam com o tempo, com a autoridade de quem fala, variam também segundo a classe social de quem os enuncia e de quem é o objeto da fala. São diferentes conforme se trate de meninas ou meninos, de bebês ou crianças maiores, de crianças de diferentes raças ou etnias, originados a partir de posições de pessoas que têm/não têm interesses diretos em sua educação, criação, etc. (p. 24)

Podemos dizer que hoje, nestes tempos por muitos considerados como pós-modernos, diferentes significados de infância estão sendo produzidos e circulam nas sociedades, criando distintas concepções de infância, múltiplos modos de descrevê-la, representá-la e lidar com ela. Além dos significados que circulam no campo social, variados artefatos e condições de possibilidade operam ininterruptamente na constituição das infâncias, de suas identidades e representações, fazendo com que inegavelmente as infâncias do início do século XXI sejam infâncias peculiares, distintas das outras e com características singulares. Como há uma gama de artefatos e de condições implicadas na constituição das infâncias, não devemos mais falar de uma infância, mas de diferentes modos de ser criança e de viver a infância. Costa (2009c) afirma que "Há muitas infâncias, todas elas construções sociais, (...) todas produzidas pelas culturas em que 
estão inscritas e marcadas por essas profundas transformações sociais, políticas, econômicas e culturais a que assistimos a partir da segunda metade do século XX.” (p.67)

Neste trabalho abordamos o significado da infância na sociedade de consumidores. Ele é um recorte de estudos que vem sendo realizados ${ }^{\mathrm{i}}$ para investigar as conexões entre cultura contemporânea, educação e escola, nos quais o consumo tem despontado como componente central. Interessa-nos mostrar aqui como a infância é produzida e representada para atender aos interesses do mercado capitalista e como a relação infância e consumo é produtiva na constituição de uma infância que temos chamado de pós-modernaii ${ }^{\text {ii }}$ Para isso, apresentaremos neste texto uma breve discussão teórica sobre a produtividade da aliança entre infância e consumo e, em seguida, analisaremos e problematizaremos como esta aliança vem sendo representada na publicidade de revistas. A seleção das revistas atendeu ao critério de ampla circulação e periodicidade semanal, resultando na escolha de publicidade veiculadas nas revistas Caras e Veja durante o segundo semestre de 2009.

\section{A aliança entre infância e consumo}

Nas obras de Jameson (1996) e Harvey (2008) sobre a pós-modernidade, e nos estudos de Bocock (2003) e Bauman (2008), entre outros, sobre consumo, temos possibilidade de verificar que o consumo nem sempre significou para as sociedades o que significa hoje. De acordo com Harvey (2008), uma nova concepção de consumo surgiu na década de 1970, com o declínio do sistema fordista e com a emergência do sistema baseado na acumulação flexível. Passa-se a produzir mais e diferentes produtos, o que faz com que os antigos sejam descartados, e produz-se em diferentes locais, de forma que as mercadorias circulem pelo mundo intensa e rapidamente. Os mercados mantêm um fluxo constante, vendendo e produzindo produtos incessantemente, e uma parcela maior da população dispõe de condições para adquiri-los, uma vez que a mão de obra mais barata, em países emergentes, e o uso de matéria prima de qualidade discutível, entre outras estratégias, reduz seu preço. Com a globalização, este modelo econômico expandiu-se pelo planeta e, 
atualmente, mais do que um fenômeno da economia, o consumo é uma condição existencial que praticamente matiza as culturas de todas as regiões e locais do globo.

Na mesma linha, Bauman (2008) afirma que hoje, sob a condição pós-moderna - que ele prefere chamar de modernidade líquida - vivemos em uma "sociedade de consumidores". Nela, o consumo se manifesta pela descartabilidade dos produtos, pela efemeridade, pela volatilidade, diferente da "sociedade de produtores" do mundo moderno, na qual o valor dos produtos se expressava por sua solidez e durabilidade.

A infância e as crianças também foram ressignificadas no interior desta nova condição que configura a "sociedade dos consumidores" de Bauman. Segundo o autor (2008, p.73):

Numa sociedade de consumidores, todo mundo precisa ser, deve ser e tem que ser um consumidor por vocação (ou seja, ver e tratar o consumo como vocação). Nessa sociedade, o consumo visto e tratado como vocação é ao mesmo tempo um direito e um dever humano universal que não conhece exceção. (grifos do autor)

Como ele afirma, esse modelo de sociedade não conhece exceção. Todos são potenciais consumidores, inclusive as crianças. Nessa configuração social, elas são vistas como sujeitos que precisam ser iniciados desde cedo nesta prática para assegurar a continuidade do modelo de sociedade.

Juliet Schor (2009) aborda exatamente essa questão em seu conhecido livro Nascidos para comprar, sublinhando que a partir da segunda metade do século XX, em especial nas décadas de 1980 e 1990, emergiu uma nova aliança, a aliança entre crianças e consumo. A produtividade das crianças para o consumo e para o mercado começa a ganhar relevância e espaço por meio das campanhas publicitárias onde o objetivo é fazer das crianças consumidores. Ao realizar sua pesquisa sobre a produtividade das crianças para o mercado de consumo norte-americano, Schor assim se manifesta:

Os arquitetos dessa cultura - as empresas de propaganda, o mercado e os publicitários de produtos de consumo - têm se voltado para as crianças. Embora elas tenham uma longa participação no do mercado consumidor, até recentemente eram consideradas pequenos agentes ou compradores de produtos baratos. Elas atraíam uma pequena parcela dos talentos e recursos da indústria e eram abordadas principalmente por intermédio de suas mães. Isso se alterou. Hoje em dia, crianças e adolescentes são o epicentro da cultura de consumo norte-americana. Demandam atenção, criatividade e dólares dos anunciantes. Suas 
preferências direcionam as tendências de mercado. Suas opiniões modelam decisões estratégicas corporativas. (SCHOR, 2009, p. 2)

Ainda de acordo com esta autora "a nova regra é que crianças e marqueteiros unam as forças para convencer os pais a gastarem dinheiro" (SCHOR, 2009, p.10). A ideia está dando tão certo que hoje o marketing mudou seu público favorito: do marketing exclusivo às mães para o marketing que enxerga a criança como consumidora em potencial - o marketing infantil.

O marketing infantil ocupa um lugar central nas agências que formam as crianças de hoje para serem consumidoras. Muitos aspectos de suas vidas são pautados por esta condição e pelo desejo de ser consumidor, papel primordial - seja para adultos ou seja para crianças - nas sociedades em que vivemos. De acordo com Bauman (1998), "A maneira como a sociedade atual molda seus membros é ditada primeiro e acima de tudo pelo dever de desempenhar o papel de consumidor. A norma que nossa sociedade coloca para seus membros é a da capacidade e vontade de desempenhar este papel.” (p. 88)

As transformações nas contemporâneas formas de consumir ultrapassam a aquisição de bens ou serviços; como dominante cultural, isto é, como uma inspiração para as formas de vida, o consumo marca indelevelmente tudo que fazemos e organiza nossa existência. É assim que consumimos também emoções, ideias, modos de ver a vida, de portar-nos, falar e pensar. É assim que além de consumir também nos transformamos em mercadorias e somos consumidos. Essa mercantilização das várias faces da nossa existência, de nós mesmos e de tudo que nos rodeia tem sido referida como comodificação ${ }^{i i i}$, que quer dizer transformar-se em commodity, em bem de consumo.

E o consumo como dominante cultural na contemporaneidade interfere diretamente na constituição da infância. Segundo Costa (2009b), "as crianças de hoje nascem dentro da cultura consumista e crescem modelando-se segundo seus padrões e suas normas" (p.35-36). Nascer na cultura consumista não significa apenas acompanhar de fora, pacificamente, a sociedade girando em torno do eixo do consumo. Para a manutenção desse sistema, as crianças são chamadas a fazer 
parte, a entrarem no jogo desde muito pequenas, garantindo sua continuidade nas futuras gerações. Cada vez mais as crianças estão enredadas na ordem do consumo. Isso é perceptível não só nas roupas e adereços que elas usam, mas no valor que dão ao fato de poderem adquirir moda, estilos e tecnologias recém lançados (mesmo que sejam réplicas ou falsificações), e no quanto são atraídas e usadas pelas estratégias de convocação ao consumo levadas a efeito pela publicidade. É sobre uma face desse fenômeno que nos deteremos a seguir.

\section{A infância na publicidade de revistas}

A descartabilidade e a efemeridade tem sido amplamente expostas e debatidas como características dos tempos atuais. Bauman $(2007,2008)$ tem se dedicado a demonstrar que são evidências da fase líquida da modernidade em que tudo flui, como os líquidos, e muda incessantemente de forma. É assim que ato de consumir exige constante movimento, pois o que o mantém é a renovação do desejo, que nunca pode ser satisfeito. O que se deseja hoje perde a importância no ato mesmo da sua obtenção e é imediatamente descartado e substituído por outro desejo. Para manter vivo o fluxo desta lógica a conjunção entre mídia e publicidade tem sido fundamental. É por intermédio dela que crianças e jovens "descobrem" as tendências consumistas do momento. Ambas são produtivas no acionamento para o consumo. Juntas, mídia e publicidade são poderosas na construção de sujeitos consumidores, particularmente, de crianças consumidoras.

Ao prefaciar o livro de Susan Linn (2006) sobre crianças do consumo, Villela (2006) expõe sobre a responsabilidade da mídia e da publicidade na convocação para o consumo: "a responsabilidade maior está nas empresas e nas agências de publicidade que apostam no mercado infantil, procurando a vulnerabilidade de cada faixa etária da infância e adolescência para criar consumidores fiéis, as crianças do consumo" (p.12). Para Linn (2006), negar a produtividade da publicidade nesta sociedade é fechar os olhos para os modos como as crianças se constituem. Sua posição é de que:

A longo prazo, essa imersão de nossos filhos na cultura comercial traz consequências que vão muito além do que eles compram ou não. O Marketing é formulado para influenciar mais do que preferências por comida ou escolhas de roupas. Ele procura afetar os valores 
essenciais como as escolhas de vida: como definimos a felicidade e como medimos nosso valor próprio. (p.29)

Schor (2009), por sua vez, argumenta que a aliança entre crianças, publicidade e consumo também altera as relações familiares. Em seus estudos, analisa a influência das crianças na hora de decidir o que os pais devem comprar, e afirma serem elas que muitas vezes determinam o modelo e a cor do carro, o que se come e o que se veste em suas famílias. Ainda segundo Schor, este poder de voz e de consumo das crianças em seu circuito familiar chama-se "mercado de influência". De acordo com a pesquisadora, isso justifica porque há campanhas publicitárias da Ford no canal Nickelodeon, um canal voltado exclusivamente ao público infantil, ou porque em um painel administrado pela agência Griffin Bacal de Nova Iorque, "100\% dos pais de crianças de 2 a 5 anos revelaram que seus filhos tiveram influência na compra de alimento e lanches rápidos" (SCHOR, 2009, p.19).

Em nosso país isso não tem sido diferente. A publicidade não dá tréguas às crianças e as usa intensamente para vender de tudo. Basta prestar atenção nas peças publicitárias de grande evidência para perceber que as crianças são acionadas para movimentar os mercados de celulares (fig. 1), medicamentos e purificadores de água (figs. 2 e 3), para recomendar concessionárias de revisão de carro (fig. 4) e, inclusive, para orientar a escolha do banco que vai guardar as economias e alcançar o dinheiro na hora das compras (fig. 5).
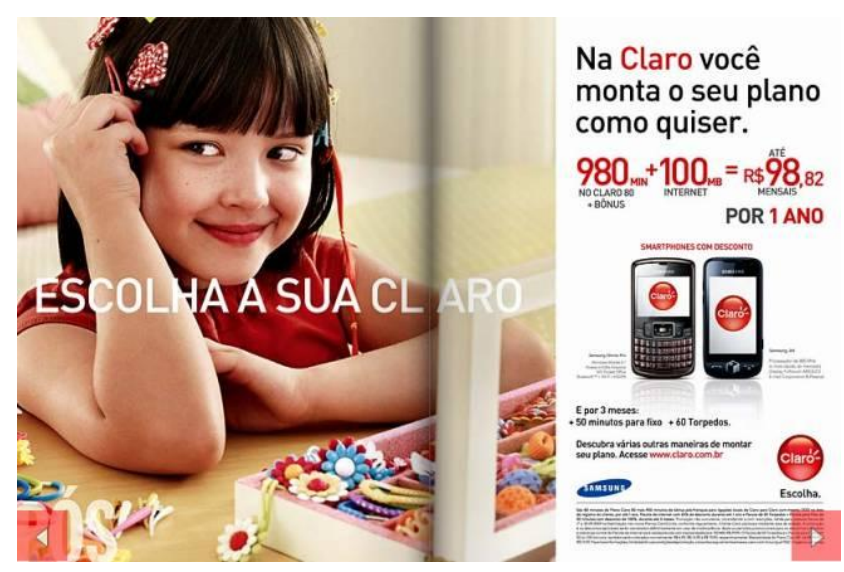

Figura 1 - Publicidade de celulares da "Claro, ,iv 


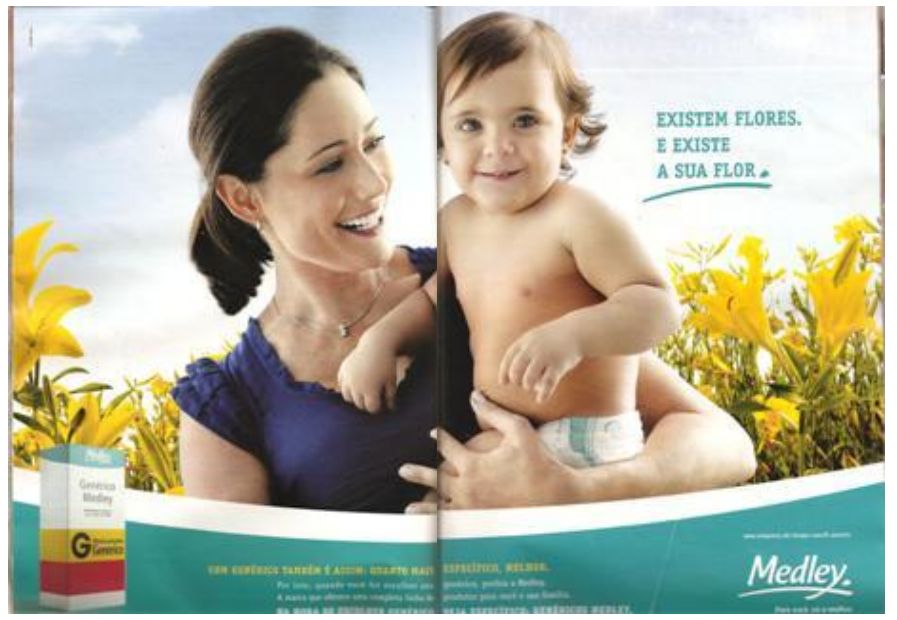

Figura 2 - Publicidade de medicamentos "Medley",

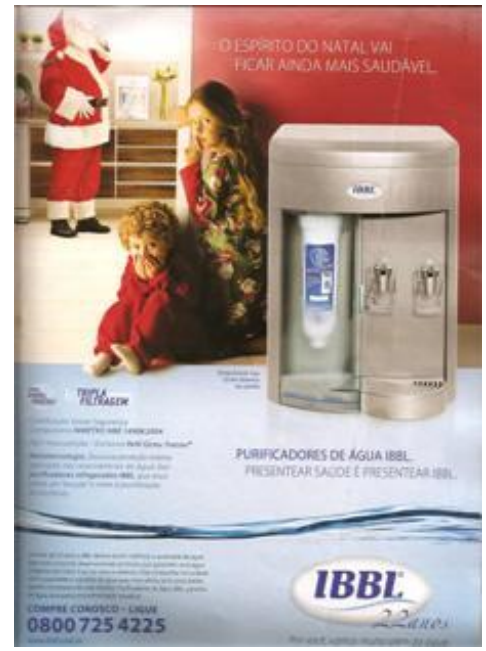

Figura 3 - Publicidade purificadores de água "IBBL"vi

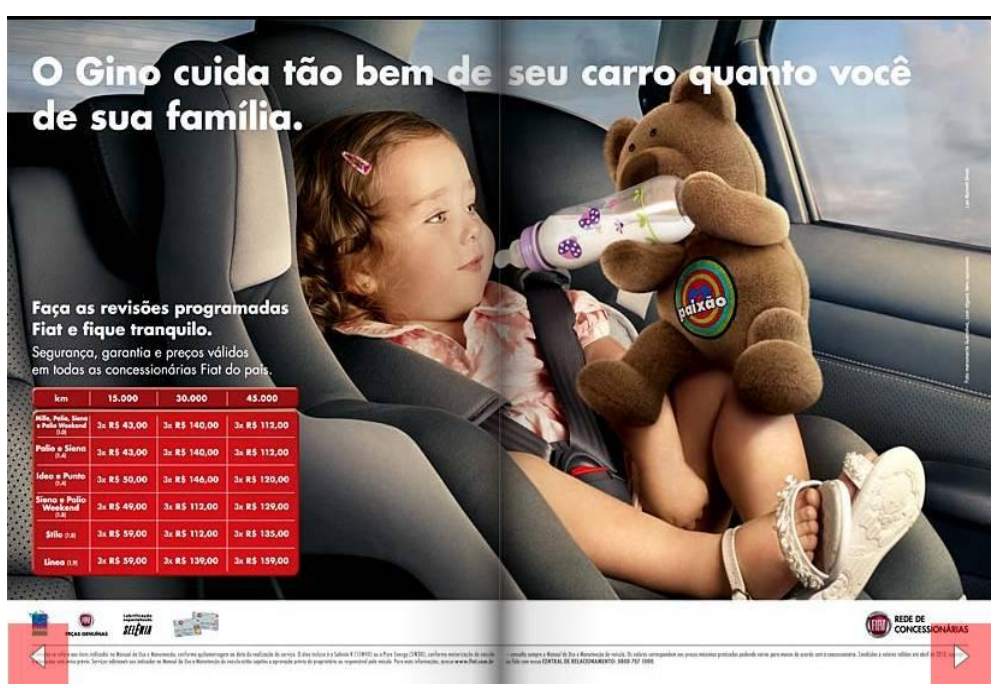

Figura 4 - Publicidade de concessionária "FIAT"vii 
Nesta nova ordem social - a sociedade de consumidores - as crianças ganham um lugar na economia pois "seu status agora é de cliente que opina, exige e consome, não necessariamente dependente do adulto" (SOUZA, FORTALEZA E MACIEL, 2009, p.22). E a transformação das crianças em consumidores ocorre independentemente da condição social ou econômica. A regra na sociedade de consumidores é que todos dela devem fazer parte, "nessa sociedade, o consumo visto e tratado como vocação é ao mesmo tempo um direito e um dever universal que não conhece exceção" (BAUMAN, 2008, p.73).

E este "não conhecer exceção" reforça o argumento de que todos podem (leia-se devem) fazer parte da sociedade capitalista e consumista. Esse argumento pode ser percebido, por exemplo, na publicidade do Banco Bradesco. Um banco $100 \%$ presente no país - conforme seu slogan - e que, portanto não conhece exceção. Além disso, o banco faz uso da infância e da noção de família patriarcal para chamar novos clientes (fig. 5).

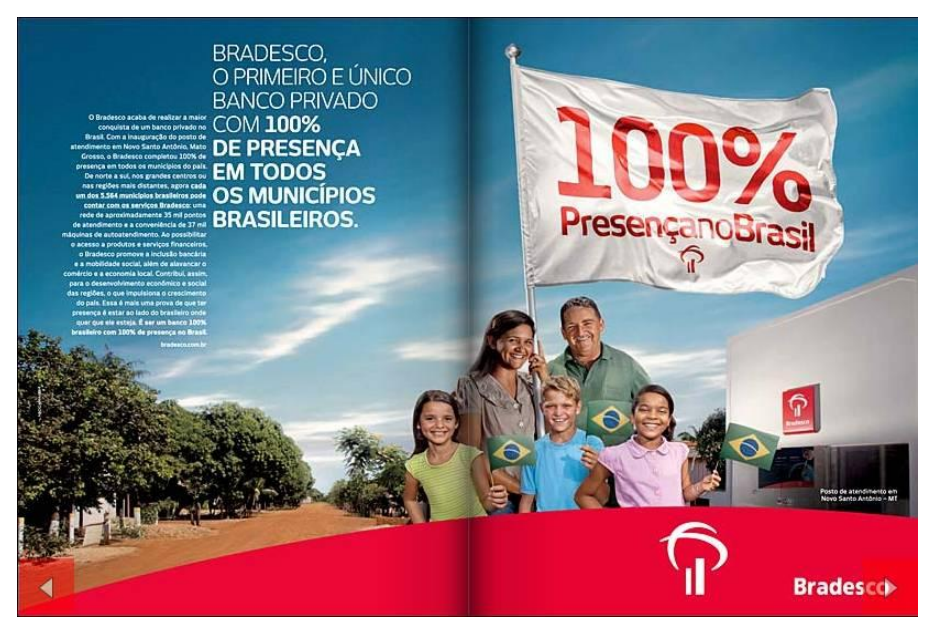

Figura 5 - Publicidade sobre ampla presença do "Banco Bradesco" no País viii

Por sua vez, campanhas publicitárias que apresentam crianças de diferentes etnias fazem parte da lógica do consumo também. Todos são representados, portanto, todos estão aptos a fazer parte desta sociedade (fig. 6) e devem também ser convocados para consumir. Neste sentido, o multiculturalismo é estratégico e conveniente (COSTA, 2009a). 


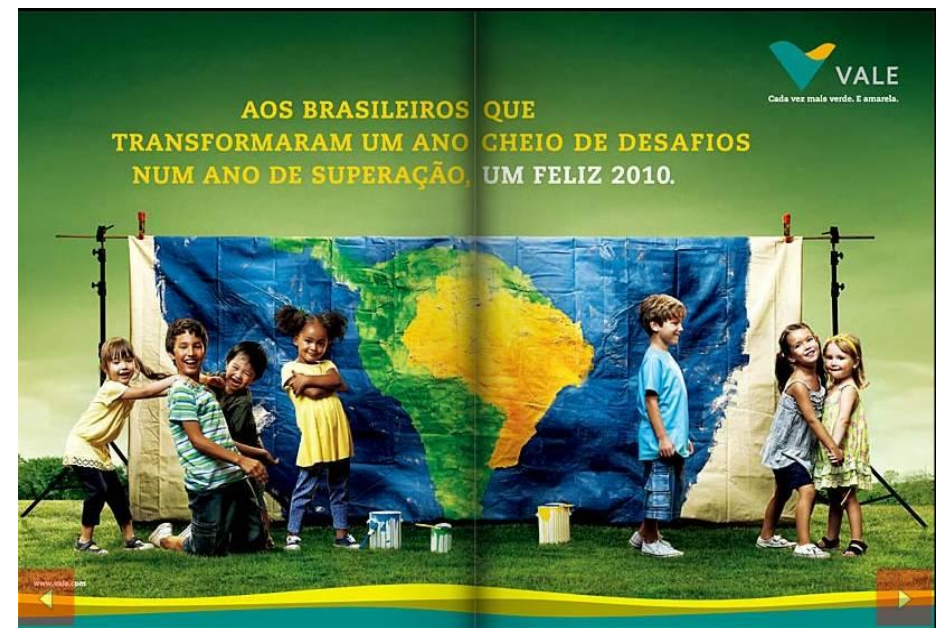

Figura 6 - Publicidade da mineradora "Vale",ix

Além disso, por todo o significado culturalmente construído que a infância tem em nossa sociedade, quando a publicidade aciona crianças para vender, não só produtos como também ideias e comportamentos, é porque sabe que isso é produtivo, como se pode observar no caso da publicidade da conhecida empresa brasileira de mineração, a Vale (fig.7). Nada melhor do que usar crianças para sensibilizar os leitores sobre a importância de se pensar sobre o futuro do planeta.

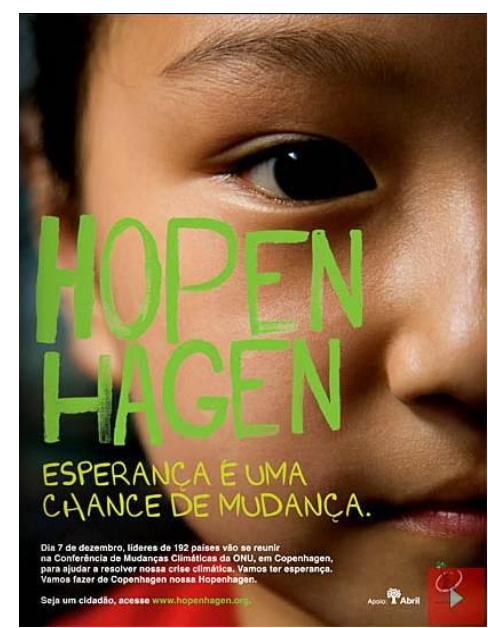

Figura 7 - Publicidade "Hopenhagen/Abril"x

Ao afirmar que as imagens infantis veiculadas na publicidade são construídas a partir de “indicadores sociais", Sampaio (2009) afirma que "isso significa que a publicidade não cria ao seu bel prazer tais imagens, mas ela resgata tendências no cenário social, selecionando e conferindo visibilidade às imagens segundo sua intencionalidade específica” (p.16).

Em âmbito nacional, temos várias campanhas que, ao aliar a infância com o consumo, tiveram grande sucesso. Aqui esboçaremos mais especificamente duas: a campanha dos "mamíferos Revista Reflexão e Ação, Santa Cruz do Sul, v.18, n2, p.230-248, jul./dez. 2010 
da Parmalat" por seu enorme sucesso; e a campanha publicitária da Melissa por toda polêmica que ela gerou ao usar e erotizar crianças nas peças publicitárias.

A campanha publicitária dos mamíferos da Parmalat $^{\mathrm{xi}}$ foi veiculada tanto nas revistas quanto nas Redes de Televisão Aberta como SBT, Rede Globo, Bandeirantes, Rede Record e Rede TV, no período de novembro de 1997 a janeiro de 2000. A promoção, que tinha previsão inicial de durar três meses, durou três anos devido ao seu enorme sucesso. Segundo Gabriele Fiore (2009), “a promoção Mamíferos de Pelúcia é considerada um dos mais bem sucedidos eventos do marketing nacional" (ver figs 8 e 9).

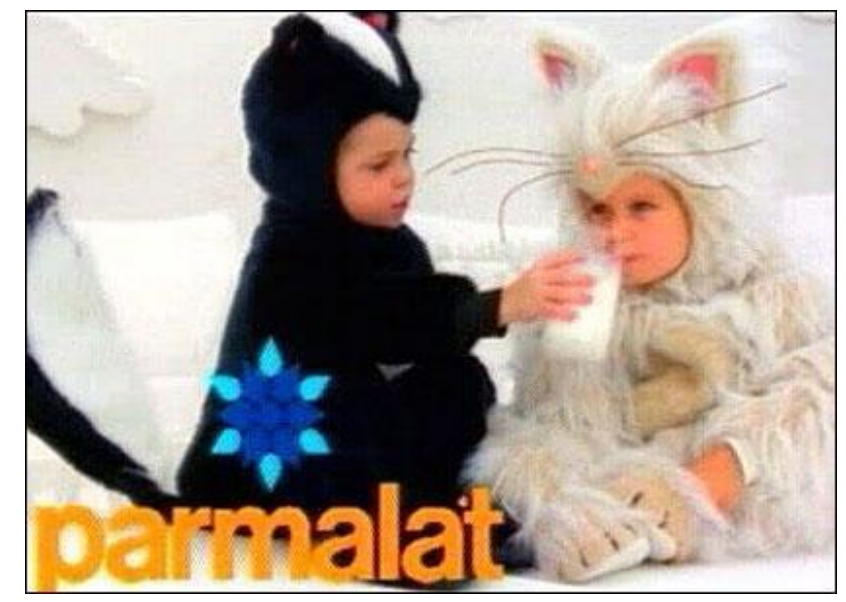

Figura 8 - Mamíferos da Parmalat - Google Imagens

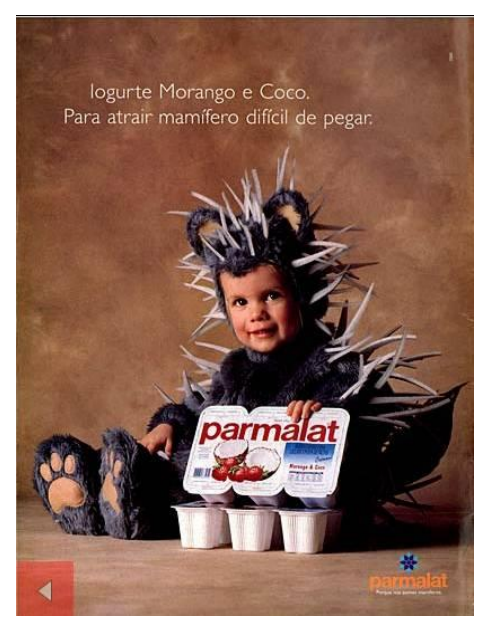

Figura 9-Publicidade "Parmalat"xii

Para obter um bichinho de pelúcia da Parmalat, o consumidor deveria juntar 20 códigos de barras de produtos Parmalat e mais oito reais para poder trocar por um dos 21 modelos de mamíferos da coleção. 
A campanha publicitária foi feita pelo brasileiro Erh Ray, então diretor de arte da agência de publicidade DM9. Os 21 atores que representavam os 21 mamíferos tinham de 3 a 5 anos de idade. O jingle da campanha aliado às crianças e aos bichinhos de pelúcia fez tanto sucesso que apenas nos primeiros 40 dias mais de 1,2 milhões de bichinhos já haviam sido distribuídos.

Conforme Gabriele Fiore (2009):

Devido ao grande sucesso, em meados de 1998, a empresa chegou até a fretar emergencialmente seis aviões cargueiros para trazer 1 milhão de unidades da China, onde são fabricadas as pelúcias. Em um único dia (5 de maio de 1998), foram distribuídos 500 mil bichinhos, a maior troca de brindes já ocorrida no país. (grifos da autora, contato eletrônico).

E esta campanha não produziu seus efeitos apenas para o sucesso dos produtos da Parmalat. Agências fotográficas foram alavancadas ao transformar cada criança em bichinhos de Parmalat em fotos tiradas com fantasias copiadas da campanha. Fábricas de roupas infantis agregaram-se ao sucesso da temática, assim como fábricas de fantasias e empresas que organizam festas infantis. Ou seja, com este exemplo da Parmalat, queremos mostrar o quanto campanhas publicitárias envolvendo crianças servem aos interesses do consumo e o quanto isso tem sido produtivo na sociedade. Mesmo que nem todos sejam interpelados da mesma maneira, muitos sentem-se convocados a entrarem nesta lógica.

Esta campanha aponta para o que Bauman (1998) e Sarlo (1997) nos dizem sobre “acumuladores de sensações" e "colecionador às avessas". Se tal promoção atingiu tamanho sucesso é porque as crianças, jovens e adultos que participaram dela não queriam apenas um mamífero, mas queriam colecionar sensações, momentos de prazer que o ato de consumir espetacularizado pode oferecer.

A outra campanha que trazemos à discussão aqui é a campanha da Melissa, sandália de plástico produzida pela Grendene e famosa entre meninas muito jovens. Foi veiculada em novembro e dezembro de 2002 nas revistas Capricho, Caras e Cláudia, endereçadas ao público feminino. Nesta campanha, meninas de diferentes grupos étnicorraciais são representadas como bonecas altamente sensuais (ver figs. 10, 11 e 12 a seguir). 
E é no próprio site da agência produtora da campanha, a W/ Brasil, que encontramos sua

descrição: “composta de 5 anúncios, a campanha foi estrelada por top models mais do que exclusivas, até porque, eram feitas do mesmo material que a própria Melissa: plástico. As bonecas, no entanto, não tinham nada de infantis"xiii.

O site ainda descreve o processo de criação campanha. Conforme a agência:

\begin{abstract}
"A gente pensou: o que aconteceria se fizéssemos bonecas de plástico com os mesmos conceitos que são aplicados na hora de criar as Melissas?", disse Rodrigo Leão, Redator da campanha. "Elas representam o multiculturalismo, a sensualidade e a diversão que inspiram o design do produto.", completou Fabio Meneghini, Diretor de Arte responsável pelo intrigante efeito visual das peças. "Fizemos uma fusão entre modelos humanas e bonecas de plástico, até chegarmos num ponto onde você não sabe mais dizer o que é humano e o que é plástico.", completou. "A campanha foi feita para lançar o novo conceito de Melissa: O plástico na sua forma mais sedutora." (Informações obtidas no site da agência W/Brasil)
\end{abstract}

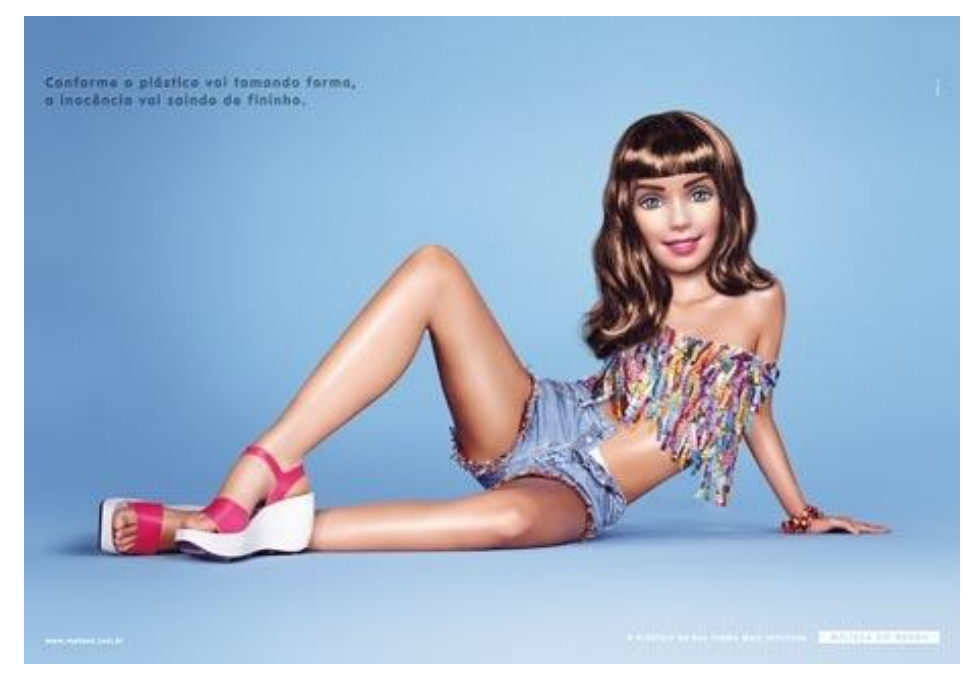

Figura 10 - Campanha Melissa "Melissa, o plástico na sua forma mais sedutora"xiv

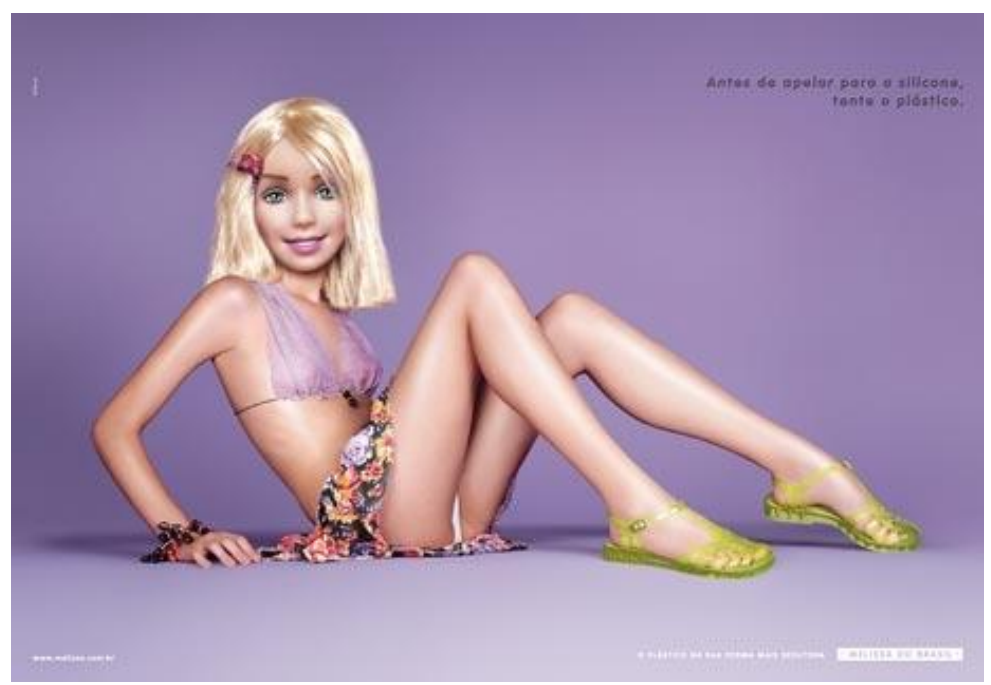

Figura 11 - Campanha Melissa "Melissa, o plástico na sua forma mais sedutora"xv 


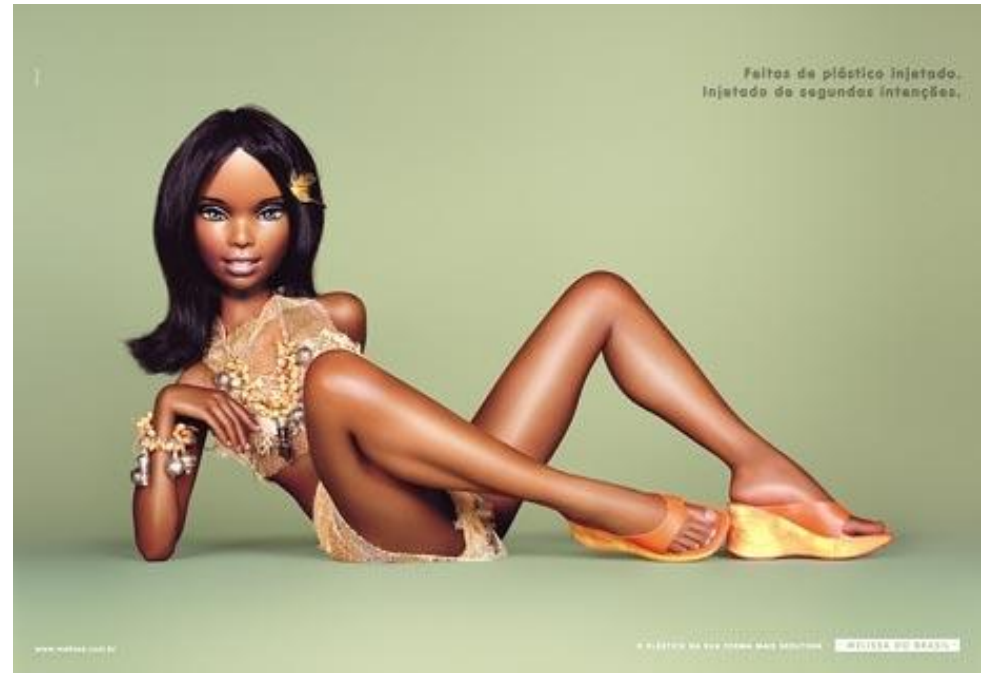

Figura 12 - Campanha Melissa "Melissa, o plástico na sua forma mais sedutora"xvi

Felipe e Guizzo (2003), ao analisarem esta campanha publicitária e refletirem sobre o fato dos rostos serem de bonecas enquanto que os corpos, mesmo com o brilho de corpos de boneca, aparentam o desenvolvimento físico, formas e proporções próprios do corpo de uma jovem garota, principalmente nos seios e quadris, acreditam que:

essa estratégia utilizada pela agência de propaganda, muito além de caracterizar simplesmente as mudanças corporais e comportamentais da menina ao entrar na puberdade, estabelecendo assim um misto de ingenuidade e sedução, tenha sido também uma forma de se preservar de possíveis acusações, na medida em que tais propagandas, de certa forma, podem estimular práticas de pedofilia. (p.7)

Apelos pedófilos, duramente condenadas nos discursos que circulam na mídia, são incitados na representação erotizada das meninas/bonecas. E mesmo recorrendo a recursos gráficos de editoração que criam um híbrido conveniente - a menina/boneca ou a boneca/menina - é a imagem da infância que está em jogo, mercantilizada, servindo a interesses e negócios corporativos. É a infância que está sendo usada para vender sandálias e, no mesmo pacote, para vender meninas e seus corpos que suscitam pensamentos e desejos não sancionados pela sociedade. E observemos que essa estratégia desponta não só na publicidade da Melissa, mas em muitas outras também (ver figs 13 e 14), onde a imagem ingênua de meninas pequenas é articulada em sutis pinceladas de erotismo esboçadas nas poses e formas de exposição de seus corpos. 
Sabemos que não há uma única forma de representação da infância e que esta muda de acordo com os interesses do mercado, do anunciante, entre tantos interesses que circulam no campo da representação. Entretanto, a representação de meninas é recorrentemente associada à menina como objeto de desejo, num misto de ingenuidade e sensualidade.

Walkerdine (1999) nos diz que falar de meninas pequenas como erotizadas é um tabu na nossa sociedade, já que os discursos sobre a infância e, especialmente sobre meninas, baseiam-se em um modelo de racionalidade que descreve a infância como ingênua e imaculada. Porém, constantemente a representação da inocência é substituída pela representação de pequenas lolitas, sedutoras e atraentes tanto na mídia quanto na mente dos adultos, o que faz o assunto ser um tabu ético e moral.

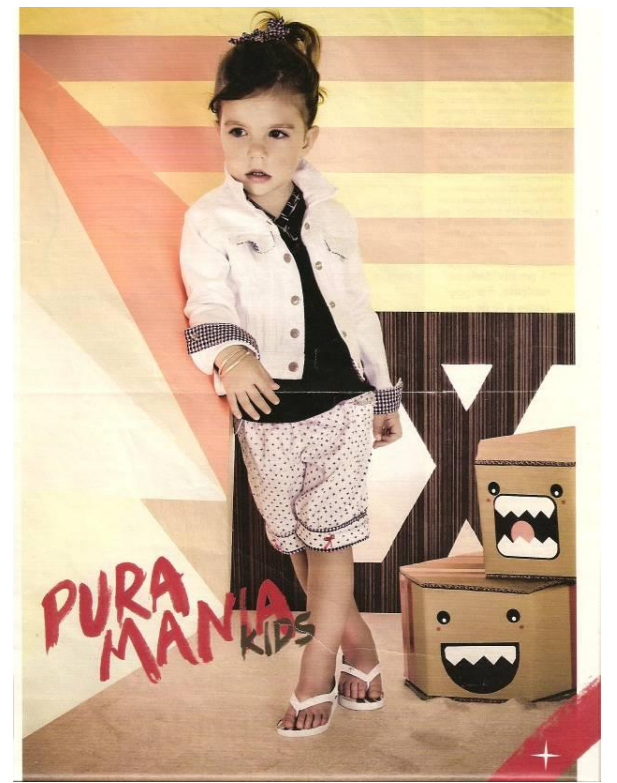

Figura 13 - Publicidade "Pura Mania Kids"”vii

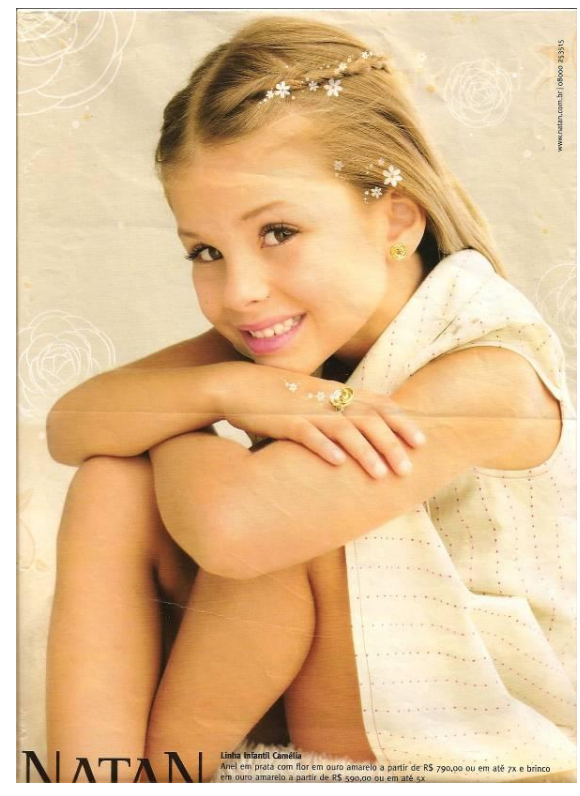

Figura 14 - Publicidade "Natan"xviii

Contudo, vemos hoje que cada vez mais empresas e marcas tem se arriscado a enveredar e investir nesse campo com o objetivo de ganhar visibilidade e, consequentemente, conquistar consumidores. Felipe e Guizzo (2003), ao pensarem sobre o acionamento e erotização das crianças para o consumo, afirmam que "ao mesmo tempo em que elas tem sido vistas como veículos que aciona o consumo, é cada vez mais presente a ideia de infância como objeto a ser apreciado, desejado, exaltado, numa espécie de 'pedofilização' generalizada da sociedade” (p.6). 
Ao trazer as campanhas da Parmalat e da Melissinha, assim como outras peças publicitárias, procuramos evidenciar o quanto a conjunção da imagem da infância com o consumo é lucrativa e conveniente aos interesses do mercado econômico capitalista. Além disso, esses poucos exemplos nos ajudam a pensar sobre como a infância é vista e tratada pelas sociedades capitalistas neoliberais das últimas décadas, expondo uma face hipócrita das retóricas e campanhas de proteção da infância. Como educadores e pesquisadores preocupados com a educação de crianças, temos condições de analisar e compreender melhor estas infâncias que nos rodeiam e os meios que tem sido acionados para produzir significados sobre elas e para elas, como é o caso da publicidade que aqui apresentamos. Sobretudo, pensamos que uma análise desse tipo pode contribuir para se refletir com mais responsabilidade sobre o sentido do nosso próprio trabalho como educadores, e sobre a imensa tarefa que temos na proteção das crianças e das infâncias de alguns usos irresponsáveis, negligentes e abomináveis que delas se faz.

\section{USING CHILDREN TO SELL: CHILDHOOD AND ADVERTISING OF CONSUMER MAGAZINES}

\section{Abstract}

In the present society, also identified as a "consumer society" (Bauman, 2008), people, irrespective of gender, age, social and financial conditions, are all called for consumption. In this article we turn to the childhood and approached one of the faces of their insertion into the society of consumers, trying to show how children are used to sell. As a frame of theoretical reference we adopt, among others, the writings of Zygmunt Bauman, Juliet Schor and Robert Bocock, dealing with contemporary versions of consumption. Analyzing weekly magazines of large circulation, we discuss how productive it is for the economic market the alliance between childhood and consumption and we argue that this use of children in publicity contributes for a new conception of 
childhood: the childhood of consumption. An erotized childhood, always wanting more and never feeling satisfied, focused in acquiring and showing off. This is the childhood that is coming to school with new interests, preferences and behavior, deserving our entire attention.

Key-words: Contemporary childhood; childhood and consumption; consumer society; advertising; magazines.

\section{Referências}

ARIÈS, Philippe. História social da criança e da família. 2. ed. Rio de Janeiro : LTC, 2006.

BAUMAN, Zygmunt. Globalização. As consequências humanas. Trad. Marcus Penchel. Rio de Janeiro: Jorge Zahar Editor, 1998.

BAUMAN, Zygmunt. Vida líquida. Trad. Carlos Alberto Medeiros. Rio de Janeiro: Jorge Zahar Editor, 2007.

BAUMAN, Zygmunt. Vida para consumo. A transformação das pessoas em mercadorias. Trad. Carlos Alberto Medeiros. Rio de Janeiro: Jorge Zahar Editor, 2008.

BOCOCK, Robert. El Consumo. Trad. para o espanhol de Beatriz Pacheco. Talasas Ediciones: Madrid, 2003.

BUJES, Maria Isabel Edelweiss. Infância e Maquinarias. Rio de Janeiro: DP\&A, 2002.

COSTA, Marisa Vorraber. O consumismo na sociedade de consumidores. In: COSTA, Marisa Vorraber (org.). A educação na cultura da mídia e do consumo. Rio de Janeiro: Lamparina, 2009 p. 33-35

COSTA, Marisa Vorraber. Leitura e diversidade. Conferência apresentada no $17^{\circ}$ Congresso Brasileiro de Leitura - COLE. UNICAMP, Campinas, 23 de julho de 2009a. (em fase de publicação)

COSTA, Marisa Vorraber. Educar-se na sociedade de consumidores. In: COSTA, Marisa Vorraber (org.). A educação na cultura da mídia e do consumo. Rio de Janeiro: Lamparina, 2009b p. 35-37

COSTA, Marisa Vorraber. A escola mantêm-se como uma instituição central na vida das sociedades e das pessoas. In: COSTA, Marisa Cristina Vorraber (org.). A Educação na cultura da mídia e do consumo. Rio de Janeiro: Lamparina, 2009c. p.61-75 
FELIPE, Jane; GUIZZO, Bianca S. Erotização dos corpos infantis na sociedade do consumo.

Revista Pro-Posições, v. 14, n.3 (42) - set./dez. 2003. p. 01-12.

FIORE, Gabriele. Serviço de atendimento ao consumidor da Parmalat. Contato eletrônico em maio de 2009.

HARVEY, David. Condição pós-moderna: uma pesquisa sobre as origens da mudança cultural. $17^{\mathrm{a}}$ ed. Trad. Adail Ubirajara Sobral e Maria Stela Gonçalves. São Paulo: Loyola, 2008.

JAMESON, Fredric. Pós-Modernismo. A lógica cultural do capitalismo tardio. Trad. Maria Elisa Cevasco e Rev. de Iná Camargo Costa. São Paulo: Ática, 1996.

MOMO, Mariangela; COSTA, Marisa Vorraber. Crianças escolares do início do século XXI - para se pensar uma infância pós-moderna. Cadernos de Pesquisa da Fundação Carlos Chagas. (artigo aprovado aguardando publicação)

SOUZA JUNIOR, José E. Gomes de; FORTALEZA, Camila H. Gazal; MACIEL, Josemar de Campos. Publicidade Infantil: o estímulo à cultura de consumo e outras questões. In: VIVARTA, Veet (coord.). Infância \& Consumo: Estudos no campo da Comunicação. ANDI; Instituto Alana: Brasília, 2009. p. 22-34.

LINN, Susan. Crianças do consumo: a infância roubada. Tradução Cristina Tognelli. São Paulo: Instituto Alana, 2006.

SAMPAIO, Inês Sílvia Vitorino. Publicidade e infância: uma relação perigosa. In: VIVARTA, Veet (coord.). Infância \& Consumo: Estudos no campo da Comunicação. ANDI; Instituto Alana: Brasília, 2009. p.09-21.

SARLO, Beatriz. Cenas da vida pós-moderna: intelectuais, arte e vídeo-cultura na Argentina. Trad. Sérgio Alcides. Rio de Janeiro: UFRJ, 1997.

SCHOR, Juliet B. Nascidos para compra: Uma leitura essencial para orientarmos nossas crianças na era do consumismo. Trad. Eloisa Helena de Souza Cabral - São Paulo: Editora Gente, 2009.

VILLELA, Ana Lúcia. Prefácio à Edição Brasileira. IN: LINN, Susan. Crianças do consumo: a infância roubada. Tradução Cristina Tognelli. São Paulo: Instituto Alana, 2006. (p.11-13)

WALKERDINE, Valerie. A cultura popular e a erotização das garotinhas. Educação \& Realidade, Porto Alegre, v. 24, n.2, jul/dez., 1999.

\footnotetext{
${ }^{\mathrm{i}}$ Trata-se dos projetos desenvolvidos por Marisa Vorraber Costa, apoiados pelo CNPq, intitulados: Quando o pós-moderno invade a escola - um estudo sobre novos artefatos, identidades e práticas culturais (2004-2007) e Consumo, mídia e espetáculo na cena pedagógica - investigando relações entre escola e cultura contemporânea (2007-2010); e da tese de doutorado de Mariangela Momo, intitulada Mídia e consumo na produção de uma infância pós-moderna que vai à escola (PPGEDU/UFRGS - 2007).

${ }^{\text {ii }}$ Ver a esse respeito o artigo de Momo e Costa (2010) intitulado Crianças escolares do início do século XXI - para se pensar uma infância pós-moderna.

iii O termo comodificação advém da expressão commodity (palavra de origem latina cujo sentido inclui o de vantagem e conveniência) que significa bem de consumo. As expressões comodificação dos consumidores e comodificação do trabalho, empregadas por Bauman (2008), referem-se à transformação tanto dos consumidores, como do trabalho, em mercadorias, em bens de consumo.

${ }^{\text {iv }}$ Fonte: Revista Veja n²129 de 09 set. 2009, p. 32-33

${ }^{v}$ Fonte: Revista Caras no 838 de 27 nov. 2009, p.100-101
} 
${ }^{\text {vi }}$ Fonte: Revista Caras n ${ }^{\circ} 838$ de 27 nov. 2009, p.159

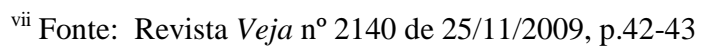

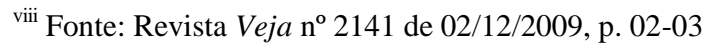

${ }^{\text {ix }}$ Fonte Revista Veja n ${ }^{\circ} 2145$ de 30/12/2009, p.72-73

x Legenda da publicidade - "Dia 7 de dezembro, líderes de 192 países vão se reunir na Conferência de Mudanças Climáticas da ONU, em Copenhagen, para ajudar a resolver nossa crise climática. Vamos ter esperança. Vamos fazer de Copenhagen nossa Hopenhagen". Fonte: Revista Veja n ${ }^{\circ} 2142$ de 09/12/2009, p.45

${ }^{x i}$ Dados coletados junto a Gabriele Fiore, do Serviço de Atendimento ao Consumidor da Parmalat em resposta a e-mail enviado por mim solicitando maiores informações sobre a campanha.

${ }^{\text {xii }}$ Fonte: Revista Veja ${ }^{\circ} 1501$ de 25/06/97 - contracapa

xiii Informações obtidas no site da agência $\quad$ W/Brasil. $\quad$ Disponível em <http://www.sitedaw.com.br/campanhas/content/top_models.wbr $>$. Acesso em 13 mai. 2010.

xiv Legenda da imagem: "Conforme o plástico vai tomando forma a inocência vai saindo de fininho". Imagem Fonte - site http://www.melissa.com.br/tudomelissa ${ }^{\text {xiv }}$. Acesso ao site em 13 mai. 2010.

xv Legenda da imagem: “Antes de apelar para o silicone, tente o plástico". Imagem Fonte - site http://www.melissa.com.br/tudomelissa.

xvi Legenda da imagem: "Feitas de plástico injetado, injetado de segundas intenções". Imagem Fonte - site http://www.melissa.com.br/tudomelissa

${ }^{\text {xvii }}$ Fonte: Revista Caras n ${ }^{\circ} 822$ de 07/08/2009 s/p

xviii Fonte: Revista Caras 829 de 24/09/2009, s/p

Data de recebimento: 05/08/2010

Data de aceite: $15 / 09 / 2010$ 